and tarsal joints" is not to admit the usefulness of the toes. Such purpose might be served if they did not exist 'and the tendons attached to them were fixed to the heads of the metatarsal bones. As it is, however, when the heel is raised the long flexors, having their tendons attached to the ends of the toes and acting on the plantar arch as bowstrings or tie.rods, have a tendency to include in that arch everything between the ends of the toes and the os calcis. In this way the heads of the metatarsal bones are uplifted and, when borne down by the weight of the body, are let down gently. Sudden and injurious pressure is thus prevented and so also is friction. Failure of this function, in varying degree and under different conditions, is the cause of callosities on the sole, of "metatarsalgia," of "Morton's Toe," and of suffering such as that described by Dr. Guthrie in THE LANCET of March 19th, 1892. Not only in these cases is there a clear surgical indication to restore the functions of the toss. It is now ten years since I first put forth in THE LANCET a plea for the study of "The Physiology of the Feet," an expression then used for the first time. ${ }^{2}$ Since then, in your columns, in "The Human F'oot" and elsewhere, I have done my best to promote it. But I am not likely to induce "shoemakers and fashion to increase the range of the usefulness of the toes," if it is to be understood that so great an authority as Sir George Humphry, eminent not only as a surgeon but as a philosophical anatomist, scarcely recognises either their usefulness or their use.

I am, Sirs, yours faithfully,

Gluucester, June 2nd, 1894. T. S. ELLIS.

\section{"PARALYSIS FOLLOWING DIPHTHERIA OF THE GENITALS ONLY."}

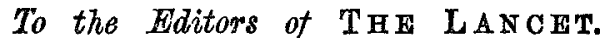

SIRs, - Corroborating the interesting case under the above heading published by Dr. Gayton in THE LANCET of May $26 \mathrm{th}$, allow me to refer to a case reported by Dr. Hill in THE LANCET of March 9th, 1889, and mentioned in my book, in which a man aged forty had false membrane on an old eczematous patch near the anus, which was followed by typical paralysis. There was no false membrane in the tinroat. The daughter of this patient, aged nine, had some weeks afterwards primary diphtheria on the vulva, which spread to the vayina and perforated the recto-vaginal wall. There was also false membrane on the throat which extended to the lung, causing death. Dr. Gayton is to be thanked for bringing forward the case, if only to qualify the statement recently made that diphtheretic paralysis does not follow except when the fauces have been previously affected, and it would be interesting to know on what rational hypothesis such an assertion can be sustained. I am, Sirs, yours faithfully,

Mansfield-street, W., May 28th, 1894. LENNOX BRowne.

\section{"TRIKRESOL FOR INHALATION."}

\section{To the Editors of THW LANCET.}

SIRS,-The interesting observations of Professor Charteris on Trikresol, communicated through THE LANCET, must have attracted the attention of many of its readers; and the important fact that trikresol is free from the poisonous qualities of carbolic acid must have suggested its great superiority in medical and surgical practice. Through the kindness of Professor Charteris I have been favoured by Messrs. Zimmerman with a specimen of Schering's trikresol, in order to ascertain whether it could be used for inhalation, as the poisonous properties of carbolic acid have for that purpose made it somewhat objectionable. My object was to determine whether trikresol when mixed with water in definite proportion wonld, like carbolic acid, when treated similarly, yield a vapour, on boiling, of definite and constant strength, a peculiarity which attaches, as I pointed out some years ago, to carbolic acid, and which makes it superior to all other antiseptics for inhalation. I find that trikresol follows the same law, as might have been expected, as carbolic acid, and that a mixture of one drachm of trikresol to one pint of water gives off, when boiled continuously, a vapour of the same strength as the mixture. This is rather strong for children, and a weaker solution may be used. To what important uses

2 THE LANCET, June 28th, 1884. this property of trikresol can be applied in the treatment of many maladies by inhalation, I hardly need point out. I am, Sirs, yours truly,

West Kensington, May 31st. ROBERT LEE

\section{"A CASE OF ADENOMA OF THE BREAST WHICH AFTER NINE YEARS DEVELOPED CARCINOMA."}

To the Editors of THE LANCET

Sins, - May I remark that Mr. Warrington Haward's case under this heading, in THE LANCE' of May 19th, illustrate the rule and not the exception, unless it may be as to the length of time? For fairly obvious pathological reasons all the connective tissue tumours which appear in the femal breast during its devolution period pass eventually into malignant stage. Most often the secondary lesion is carcinoma, as in the case cited; less commonly it is spindle celled sarcoma. The former springs from the epithelium of the included acini, which dilated form the always numerous cysts ; the latter from the redundant fibrous tissue base. think the time within which the fatal modification ensues averages five to six years; in an instance of the last-named order, now under my care, it was only four years. The important practical point, however, with which I am here concerned is the differentiation of these tumour from the outwardly similar "lumps" manifest during the development of the mammæ-i.e., in young girls. The former always, sooner or later, verge into cancerous disease, the latter never. The former rarely fail to undergo resolution under appropriate local treatment without resort to operation; the latter imperatively need early excision. The former I have never yet found in association with cyst forma. tion; the latter are always full of innumerable cysts, some large, some microscopic, a thin section being recognisable at a glance by its oribriform appearance. The former are often multiple; the latter always single. With such significant clinical points of distinction it becomes peculiarly necessary not to confuse these two essentially different lesions under an ambiguous title common to both. The term "fibro-adenoma" might thus be discarded with conspicuous advantage: the harmless adenoid thickening seen in young girls is appropriately described as the "fibroma of adolescence" ; the far more serious disease of middle-aged women should, in accordance with its most salient characteristic, be styled "cystic fibroma." I am, Sirs, your obedient servant,

Gloucester-place, Portman-square, w. HERBERT SNow.

\section{HEALTH RESORLS AND INFECTIOUS DISEASES. \\ To the Editors of THE LANCET.}

SIRS,-It is not to be wondered at that there is still much criticism of the notification system and even some doubts as to the utility of it. The enormous epidemics of notifiable disease through which we are passing are proof enough that it is not so efficient for prevention of disease as we should expect it to be. We can only perserere in attempts to make it work smooth]y and efficiently. Surely some more public use of notification should be practicable, especially in regard to places which we regard as health resorts. I think the time is opportune for asking you, before the holidays, to use your influence to secure that these places do not become disease resorts. Let me illustrate my meaning. Last year one of my patients, with seven small boys, went down to a popular seaside place, which shall be nameless. Four of them took scarlet fever there at such dates as to make it certain that it was caught in the place. and probably in the house. His expenses were great, ard the oldest of the four nearly died. I reported these facts to the medical officer of health, who replied with great courtesy and, I think, suspected the fons et origo mali, but could not satisfy himself or give any information that could lead to the detection of the culprit. A medical friend told me a few days ago that he took a house in a well-known place on the Thames for the benefit of his family. Four of them took diphtheria in the house, and one typhoid ferer. Gross defects of drainage in the honse and the adjoining honse were discovered. Surely, with all our sanitary laws and their costly administration, such accidents should become rarer. I would suggest that a visitor, in taking a bouse at 